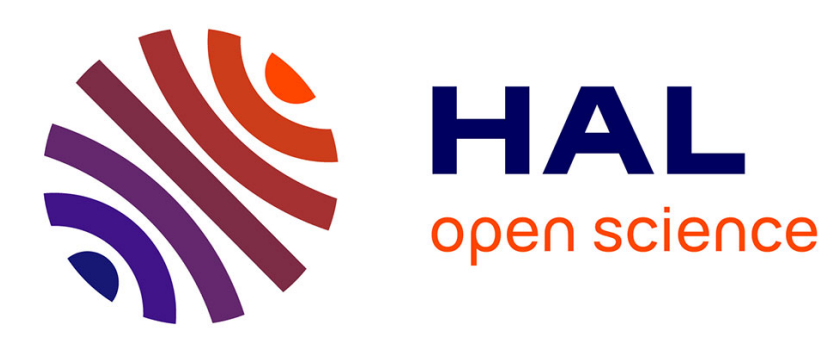

\title{
The carbon-constrained EOQ model with carbon emission dependent demand
}

\author{
V Hovelaque, L Bironneau
}

\section{To cite this version:}

V Hovelaque, L Bironneau. The carbon-constrained EOQ model with carbon emission dependent demand. International Journal of Production Economics, 2015, 164, pp.285-291. 10.1016/j.ijpe.2014.11.022 . halshs-01103463

\section{HAL Id: halshs-01103463 \\ https://shs.hal.science/halshs-01103463}

Submitted on 14 Jan 2015

HAL is a multi-disciplinary open access archive for the deposit and dissemination of scientific research documents, whether they are published or not. The documents may come from teaching and research institutions in France or abroad, or from public or private research centers.
L'archive ouverte pluridisciplinaire HAL, est destinée au dépôt et à la diffusion de documents scientifiques de niveau recherche, publiés ou non, émanant des établissements d'enseignement et de recherche français ou étrangers, des laboratoires publics ou privés. 


\title{
The carbon-constrained EOQ model
}

\section{with carbon emission dependent demand}

\author{
V. Hovelaque ${ }^{1}$ \\ Full Professor \\ vincent.hovelaque@univ-rennes1.fr

\section{Bironneau} \\ Associate Professor \\ laurent.bironneau@univ-rennes1.fr
}

\section{IGR-IAE of Rennes (University of Rennes 1), CREM UMR CNRS 6211}

11 rue Jean Macé, CS 70803 - F 35708 Rennes cedex (France)

1. Corresponding author.

Tel. +33223235413 .

Fax. +33223237800

\section{ABSTRACT}

Currently companies are looking for solutions to reduce carbon emissions associated with their operations. Operational adjustments, such as modifications in batch sizes or order quantities, have proven to be an effective way to decrease emissions. In this paper, a novel model is proposed that takes into account the link between an inventory policy (EOQ), total carbon emissions, and both price and environmental dependent demand. In the case of an exogenous price, two optimal quantities are determined which maximize a retailer's profit and which minimize carbon emissions. Conditions that allow a company to maximize profit while minimizing emissions and mechanisms that allow a firm to maximize its profit and to decrease its carbon emissions are determined. In the case of an endogenous price, some empirical results are also discussed. When a firm optimizes its profit through both its selling price and its order quantity, some experiments match empirical observations. On the one hand, an environmental strategy is more significant for cheaper and green-labeled products. On the other hand, a public mechanism such as a carbon tax will decrease total and marginal emissions.

Keywords: Inventory; EOQ; environmental awareness; carbon emission; carbon tax. 


\section{Introduction}

Currently companies are increasingly sensitive and responsive to the carbon emissions (emissions of carbon dioxide and other greenhouse gases) associated with their operations (Cholette and Venkat, 2009; Stock et al., 2010). Under the influence of their customers, who increase their socially responsible consumption practices (Gonzalez et al., 2009), and also of governments and other pressure groups, they are undertaking initiatives to reduce their carbon footprint. In a recent paper Chen et al. (2013) note that firms have focused for the most part on reducing emissions through innovations of the physical processes involved, for example by redesigning products and packaging, deployment and use of less polluting sources of energy, or replacing energy inefficient equipment and facilities... For example, determining how frequently supply deliveries are made could be as important in mitigating carbon emissions as the energy efficiency of the vehicles used to make these deliveries (Benjaafar et al., 2013). Operational adjustments, such as modifications in batch sizes or order quantities, have proven to be an effective way to reduce carbon emissions impact (Cholette and Venkat, 2009; Hua et al., 2011; Bouchery et al., 2012; Chen et al., 2013). Thus, in recent years, green and sustainable supply chain management have been studied thoroughly, as evidenced by the literature review of Seuring (2013). In the following state of the art, we will focus on papers dealing with sustainability modeled in inventory management, demand and vertical coordination.

Hua et al. (2011) propose an environmental approach to inventory management that integrates the impacts of a carbon cost associated with both order placement (mainly transport) and holding stock (storage). The proposed model extends the Economic Order Quantity model (Harris, 1913; Wilson, 1934) to take into account carbon emissions under the cap and trade system. They conclude that the optimal order quantity is between the classically calculated economic quantity (without taking into account the $\mathrm{CO} 2$ cost) and the quantity that minimizes carbon emissions. They also prove that there exist some conditions to decrease both economic costs and carbon emissions. Wahab et al. (2011), meanwhile, offer an approach to optimally define the delivery / production policy to minimize the total cost of supply in a global supply chain. They show that taking into account the environmental impact leads to reducing the frequency of deliveries. Bonney and Jaber (2011) show that increasing the amount of products transported and reducing the frequency of delivery compared to those proposed by the traditional EOQ model gives better results in terms of ordering costs and carbon emissions. 
However the latter two models are more limited than that of Hua et al. (2011); they do not take into account the "cap and trade" system, and are also limited to the study of the reduction of $\mathrm{CO} 2$ emissions in transport, (emissions associated with storage are not considered). Bouchery et al. (2012) propose to integrate all the parameters of sustainable development (SD), including the social aspect missing from other works, into inventory management models. They reformulate the classic economic order quantity model as a multi-objective problem (called the sustainable order quantity model - SOQ). It follows two main points of their work. Firstly, that it enables reducing any SD impact by requiring a small increase in cost, which is in accord with the results in Hua et al. (2011). Secondly, it is sometimes not possible to have overall environmental, economic and social efficiency, which led them to propose a trade off between various parameters.

Chen et al. (2013) provide conditions under which, first, it is possible to reduce emissions by modifying order quantities and, second, the relative reduction in emissions is greater than the relative increase in cost. This paper is also interesting because the authors discuss the applicability of their results to systems under a variety of environmental regulations, for example settings with a carbon tax, cap-and-offset, and cap and price. Battini et al. (2014) propose a sustainable EOQ model by integrating environmental impacts of transportation and storage. They assess the impact of sustainability considerations on purchasing decisions in comparison to a traditional EOQ model. In particular, for the same transportation modality, there is no significant difference between the traditional and the sustainable model, but this difference increases with an increasing product price.

El Saadany et al. (2011) studied a simple two-echelon supply chain model in which demand depends on the environmental quality of the systems (measured using thirty criteria) and the associated costs. Glock et al. (2012) present a model that illustrates the trade-offs between sustainability, demand, costs and profit in a supply chain. They show that stakeholders can attract more customers by controlling emissions and scrap. Moreover, the total profit is higher but the product quality is lower in the case of cooperation. Nouira et al. (2013) propose a nonlinear profit function that takes into account a greenness dependent demand. The selection of manufacturing processes (technology) and input items allows optimizing a profit function in the case of an environmental dependent demand. In particular, they show that a firm increases its profit and decreases its carbon footprints if its faces to both an ordinary and green market.

Liu et al. (2012) also develop a model that includes consumer environmental awareness and 
competition (three supply chain scenarii). They find that stakeholders with superior ecofriendly operations will benefit from an environmental demand increase. Some other results are proposed based on the eco-friendly level of manufacturers and retailers. Ghosh and Shah (2012) examine some supply chain coordinations with players initiating product "greening". Cooperation between stakeholders does lead to higher greening levels but also to higher retail prices. In some coordination cases, the retailer has to provide suitable incentives to the manufacturer form him to participate in the bargaining process. Swami and Shah (2013) develop a model with a manufacturer and a retailer that coordinate their operations (wholesale price and green effort for the manufacturer, market price and green effort for the retailer). They propose a two-part tariff contract to produce channel coordination and 'greener' efforts. The majority of articles have focused on the minimization of the total cost supported by the manufacturer/retailer by introducing in the EOQ model some costs parameters linked to environment considerations. To take into account consumer's environmental awareness, some articles introduce an independent environmental parameter in a deterministic demand function (defined as the manufacturer's effort to be less polluting). To our knowledge, no model proposes to introduce the carbon emissions directly in the demand function, complementary to price sensitivity. Such a model is of interest because (i) some retailers developed a carbon labeling on their products linked with the emissions (Casino in France and Tesco in Great Britain), (ii) stock policy will impact carbon emission and then both economic profit and consumer's attractiveness and (iii) the retailer's environmental strategy should affect the price of the product. As proved in several surveys, the consumer is increasingly attracted by less polluting products, even if the price factor remains the first criteria of purchase.

The purpose of this paper is to address this gap by proposing a novel model that takes into account the link between inventory policy, total carbon emissions and both price and environmental dependent demand. We study the structure in two steps: first, the retailer maximizes its profit through the economic order quantity solely; secondly, through EOQ and price. In the first step, the mathematical model addresses the conditions that allow a firm to maximize its profit and to minimize its carbon emissions. We find that a carbon tax is always beneficial to the environment (lower emissions), to the consumer (higher demand) but unfavorable to the retailer (lower profit). Furthermore, an increase in the carbon price (cap and trade mechanism) has the same effects excepted on the retailer's profit that should increase or decrease depending on the parameters. Depending on certain conditions, total emissions should increase as one cost parameter increases (ordering or holding cost). This 
result shows that, for instance, a higher price of oil (picked up by the ordering cost) could generate more emissions. Finally, above a specific threshold, the retailer may increase its profit with an increasing consumer's awareness but may be penalized if the awareness becomes too high. For this first step, we also analyze the behaviour of the marginal rate of carbon emissions. To our knowledge, this performance indicator was not studied in literature. Its evolution is not necessarily similar to that of $\mathrm{CO} 2$. Thus, we show that, in some situations, the amount of $\mathrm{CO} 2$ emitted decreases while the marginal rate increases. This phenomenon is related to the independent evolution between demand and emissions. In a second step, some empirical results are discussed in case of an endogenous price. If price elasticity increases, the retailer will reduce its price to increase its demand. For some parameters, this generates a higher $\mathrm{CO} 2$ amount. Moreover, an increase of the carbon tax leads to a decrease in the emissions but entails a higher price and a higher marginal rate. Thus, this work highlights some ambiguities of environmental strategies: a decrease of the carbon emissions could lead to a higher price supported by consumers. Moreover, the marginal rate decreases in some cases because of a lower demand.

This paper is organized as follows. Section 2 introduces the mathematical model. In section 3 , the optimal quantities that maximize the profit and minimize the emissions are derived in the case of an exogenous selling price. Then, conditions are determined to both a profitmaximization and an environmental minimization. We also analyze behaviors of profit and emissions with some parameters evolutions. In section 4, some results with an endogenous selling price are presented. Finally, this leads over the discussion of the findings and future research opportunities.

\section{The model}

In this work, a retailer buys a single product at a wholesale price $r$ and sells it at a unit price $w$ on a single channel defined by a deterministic demand $D$ uniformly distributed in time (no hazard). The classical inventory management policy determines the economic order quantity (EOQ) that maximizes the profit function:

$$
P(Q)=(w-r) D-\left(k \frac{D}{Q}+h \frac{Q}{2}\right)
$$

with $Q$ as the order size in units (a decision variable), $D$ as the total demand, $k$ as the fixed ordering cost per order, and $h$ as the constant inventory holding cost per product unit and time 
unit. This approach has undergone many developments and research articles since the original work of Harris (1913). For instance, Andriolo et al. (2014) and Glock et al. (2014) produced literature reviews on the EOQ model and its many adaptations. It is also possible to consider the many published papers on this model, it's evolution and potential research perspectives in the special issue "Celebrating a century of the economic order quantity model in honor of Ford Whitman Harris" published by the International Journal of Production Economics in 2014 (Cárdenas-Barrón et al., 2014).

Stock et al. (2010) show that transport and warehouse operations generate large amounts of carbon emissions. Like the cost function above, the emission function models a trade-off between the frequency of delivery (increasing emissions of transport and decreasing emission of storage) and the storage amount (decreasing emissions of transport and increasing emission of storage). Among the methodologies, which calculate carbon emissions, the Greenhouse Gas protocol (2012) developed a linear function that depends on a fixed coefficient and a variable part. Thus, referring in particular to Hua et al (2011) and Bouchery et al (2012), the total carbon emission function (in tons) linked to delivering and storing products is then defined by the formula:

$$
C \mathrm{O}_{2}(Q)=e \frac{D}{Q}+g \frac{Q}{2}
$$

where $e$ is the unit carbon emission linked to a replenishment's order and $g$ the unit variable emission in warehouse (related to inventory quantity). This function follows the classical mechanisms (trade-offs) of the EOQ model applied to carbon emissions: emissions linked to storage increase with $Q$ whereas emissions linked to frequency (transport) decreases.

Thus, objective is to determine the optimum order quantity $Q$ maximizing the function:

$$
\operatorname{Pr}(Q)=P(Q)-t . \mathrm{CO}_{2}(Q)
$$

where $t$ is the carbon tax per unit ( $€ /$ ton).

In this paper, the inventory model is developed with a deterministic demand function:

$$
D(Q)=\alpha-\beta w-\delta C O_{2}(Q)
$$

With $\alpha$ as the maximal market demand (end consumer demand), $\beta$ as the price's sensitivity ( $w$ as unit price) and $\mathrm{CO}_{2}$ as the amount of carbon emissions defined previously and associated with elasticity $\delta$. This function takes into account the attractiveness of a product according to 
two criteria: its selling price and the amount of carbon emitted to deliver it. This second criterion is currently highlighted by retailers with eco-labeling, e.g. carbon labeling by Casino in France and Tesco in Great Britain (Upham et al., 2011) and sustainable strategies (Chitra, 2007; Liu et al., 2012). This kind of demand function has been widely used to incorporate quality and price impacts on the demand (Tirole, 1988). Moreover, Lau and Lau (2003) show that, for a single-echelon system, any downward-sloping demand curve leads to conclusions similar to a linear price-demand relationship.

The demand function can, in turn, be rewritten using the formulas (2) and (4):

$$
D(Q)=\frac{Q(2 \alpha-2 w \beta-2 g \delta-Q g \delta)}{2(Q+e \delta+Q e \delta)}
$$

Moreover, following Hua et al (2011), a cap-and-trade system is modeled by $\mathrm{CO}_{2}(Q)+X=Z$ where $Z$ is the total carbon emissions quota (ton) and $X$ is the transfer quantity of carbon emissions (positive or negative). Introducing a unit price $s$ of carbon $(€ /$ ton), the economic function of the retailer with the following profit function is defined as:

$$
\operatorname{Pr}(Q)=(w-r) D(Q)+s Z-\left(k \frac{D(Q)}{Q}+h \frac{Q}{2}+(t+s) C O_{2}(Q)\right)
$$

Because the consumer demand is modified with some parameter evolutions, it will also be of interest to observe the impact of inventory strategies on the marginal rates of greenhouse gas emissions defined by the performance indicator:

$$
\kappa(Q)=\frac{C O_{2}(Q)}{D(Q)}
$$

This model addresses (i) the conditions that allow a retailer both to maximize its profit and to minimize its carbon emissions and, (ii) mechanisms that encourage the retailer to decrease its emissions while maximizing its profit. In the first step (section 4), the model is analyzed in the case of an exogenous price $w$. In the second step (section 5), the retailer optimizes its profit with both the order quantity and price (endogenous).

\section{Analysis with an exogenous price}


The following property states the optimal conditions for both profit maximization and carbon emission minimization.

\section{Proposition 1.}

Order quantities maximizing profit (6) and minimizing emissions (2) are given by:

$$
\begin{aligned}
& Q_{p}^{*}=\underset{Q}{\arg \max }\{\operatorname{Pr}(Q)\}=-e \delta+\frac{\sqrt{A(k+e \lambda)(h+g \lambda)}}{h+g \lambda} \\
& Q_{e}^{*}=\underset{Q}{\arg \max }\left\{\mathrm{CO}_{2}(Q)\right\}=-e \delta+\frac{\sqrt{e g A}}{g}
\end{aligned}
$$

with $A=2 \alpha-2 w \beta+e g \delta^{2}$ and $\lambda=s+t+\delta(w-r)$.

Moreover:

$$
\underset{Q}{\arg \min }\{\kappa(Q)\}=Q_{e}^{*}
$$

(all proofs are developed in Annex).

Obviously, the two optimal quantities verify the two following properties $\operatorname{Pr}\left(Q_{p}^{*}\right) \geq \operatorname{Pr}\left(Q_{e}^{*}\right)$ and $\mathrm{CO}_{2}\left(Q_{p}^{*}\right) \geq \mathrm{CO}_{2}\left(Q_{e}^{*}\right)$. The result on marginal emissions is also of interest. If some parameters behaviors generate an increasing difference between the two optimal quantities, then the system may be more polluting. There is a large consensus that the first objective of retailers is to maximize their profit. Nevertheless, the structure of the logistic costs and the carbon emissions impacts the two optimal quantities relative to each other, as stated in the following theorem.

\section{Theorem 1.}

If $g / e=h / k$ then $Q_{p}^{*}=Q_{e}^{*}$ (case 1)

If $g / e<h / k$ then $Q_{p}^{*}<Q_{e}^{*}($ case 2$)$

If $g / e>h / k$ then $Q_{p}^{*}>Q_{e}^{*}($ case 3$)$. 
Notice that this result matches with theorem 1 of Hua et al. (2011). A cost analysis allows understanding this result. Consider $C(Q)=k \frac{D}{Q}+h \frac{Q}{2}$ and $E(Q)=e \frac{D}{Q}+g \frac{Q}{2}$. Minimize these functions are equivalent to minimize $\frac{D}{Q}+\frac{h}{k} \frac{Q}{2}$ and $\frac{D}{Q}+\frac{g}{e} \frac{Q}{2}$. Then, when the relative emission (storage / ordering) is greater than the relative cost, the optimal quantity is greater. The relative position of $Q_{p}^{*}$ and $Q_{e}^{*}$ is not only dependent of inventory costs and unit levels of carbon emissions but also independent of consumer environmental awareness.

In the following subsection, impacts of the carbon tax, inventory costs and environmental sensitivity are analyzed.

\subsection{Impact of carbon tax and price}

The main objective of the carbon tax, considered as a public mechanism (like the cap and trade tool with the unit carbon price), is to contribute to the decrease in the amount of $\mathrm{CO} 2$ emitted through industrial (production and logistics) activities. As expressed in theorem 1, the policy of profit maximization is not optimal for minimizing $\mathrm{CO} 2$ emissions, except in the first case. Indeed, if $g / e=h / k$, then $Q_{p}^{*}=Q_{e}^{*}$ and the retailer optimizes both its profit (maximization) and carbon emissions (minimization). A carbon tax is then ineffective in that case. In the two other cases, an increase of the carbon tax generates lower emissions of greenhouse gases, an increase in demand, but a decrease in the profit of the retailer. This is summarized in the next proposition.

\section{Proposition 2.}

For all parameters configuration: $\frac{\partial \operatorname{Pr}\left(Q_{p}^{*}\right)}{\partial t} \leq 0, \frac{\partial D\left(Q_{p}^{*}\right)}{\partial t} \geq 0, \quad \frac{\partial C O_{2}\left(Q_{p}^{*}\right)}{\partial t} \leq 0$.

Moreover $\operatorname{sgn}\left(\frac{\partial Q_{p}^{*}}{\partial t}\right)=\operatorname{sgn}(e h-g k)$.

This result can be explained in Figure 1. Consider the situation where $g / e<h / k$, i.e. $Q_{p}^{*}<Q_{e}^{*}$. First, as proved in theorem $1, Q_{e}^{*}$ is independent of $t$. For an initial level $t_{0}$ of 
carbon tax, $Q_{p}^{*}\left(t_{0}\right)<Q_{e}^{*}$. If the tax increases $\left(t_{1}>t_{0}\right)$, the profit curve shifts to the right with a new optimum $Q_{p}^{*}\left(t_{1}\right)>Q_{p}^{*}\left(t_{0}\right)$, which is closer to $Q_{e}^{*}$. Note that $Q_{p}^{*}$ tends to $Q_{e}^{*}$ when the carbon tax tends to infinity (this is not always compatible with a positive profit of the retailer).

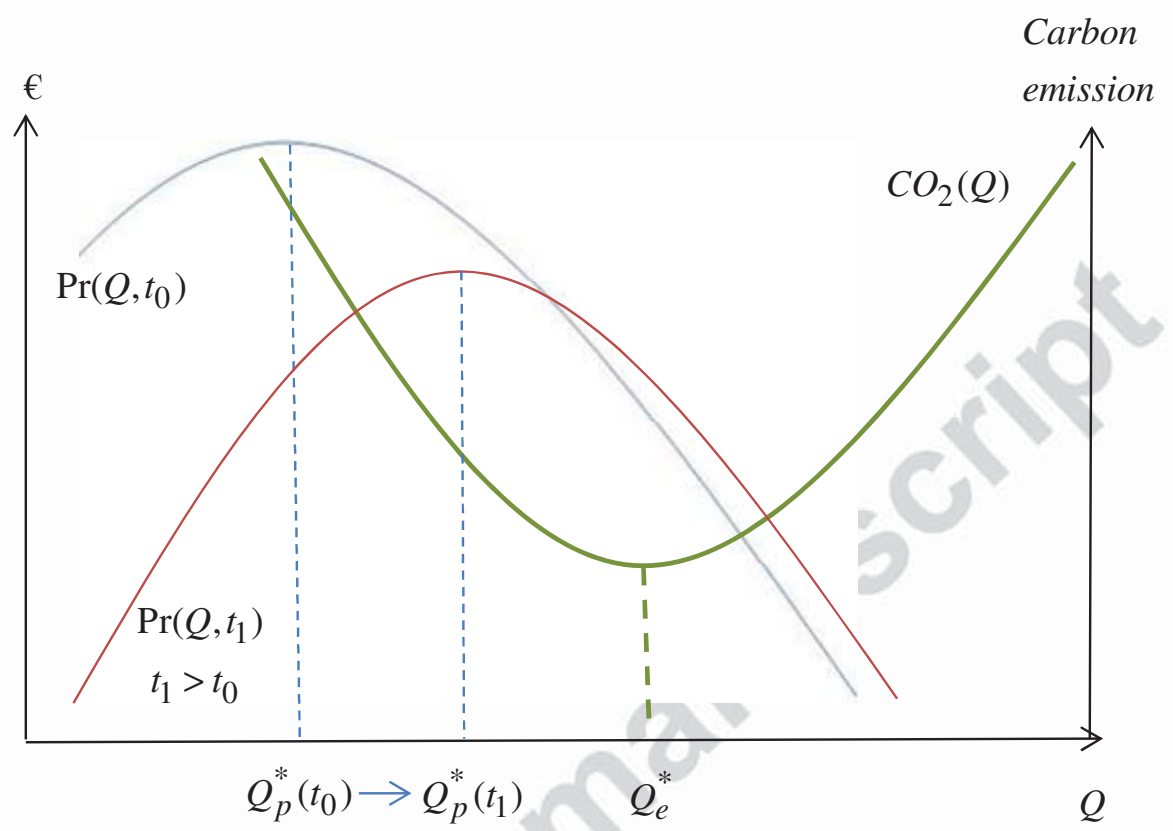

Figure 1. Impact of an increase of the carbon tax

Proposition 2 also proves that the performance indicator expressed in (7) will then always decrease if the tax increases. Thus, a carbon tax has a dual benefit: to improve sustainability of inventory management, and also to increase consumer demand towards more sustainable products.

\section{Proposition 3.}

For all parameters configurations:

$\operatorname{sgn}\left(\frac{\partial Q_{p}^{*}}{\partial s}\right)=\operatorname{sgn}(e h-g k) ; \frac{\partial D\left(Q_{p}^{*}\right)}{\partial s}>0 ; \frac{\partial C O_{2}\left(Q_{p}^{*}\right)}{\partial s}<0$

Moreover, $\quad$ if $Z>\sqrt{e g A}-e g \delta$, there exists a value of $s$ such that $\frac{\partial \operatorname{Pr}\left(Q_{p}^{*}\right)}{\partial s}=0$. 


$$
\text { If } Z \leq \sqrt{e g A}-e g \delta, \frac{\partial \operatorname{Pr}\left(Q_{p}^{*}\right)}{\partial s}<0
$$

The two above propositions show that the two mechanisms (tax and carbon prices) have not the same impacts on the retailer. Both mechanisms reduce the total amount of carbon emissions and increase the final demand. Obviously, a carbon tax always reduces the retailer's profit. This is not the case with the cap-and-trade mechanism that should advantage or penalize the retailer in function of the carbon quota $Z$ and the unit price of carbon $s$. That is interesting to note that the threshold at which profit should increase with a sufficient high $s$ is equal to $\mathrm{CO}_{2}\left(Q_{e}^{*}\right)$. Then, if the quota is less than $\mathrm{CO}_{2}\left(Q_{e}^{*}\right)$, the retailer has to buy carbon credit and this purchase increases with $s$, and has a negative impact on the profit. Otherwise, if the quota and the carbon price are relatively high, the retailer can improve its profit by selling carbon credit on the market without deteriorating its carbon emissions.

\subsection{Impact of ordering and holding costs}

In a supply chain, the strategy of lower cost storage generally requires a search of lower costs of holding inventory $(h)$ and/or of ordering $(k)$. The decrease of these costs generates a change in inventory policy (favoring either more possession or more delivery frequency). In our model, such a policy change will impact the amount of greenhouse gas emissions, and therefore demand. The following proposition shows that an increase or decrease of inventory costs can generate an increase in GHG emissions.

\section{Proposition 4.}

The carbon function is not monotonous with the ordering cost and the holding cost. In particular, $\mathrm{CO}_{2}\left(Q_{p}^{*}, k\right)$ and $\mathrm{CO}_{2}\left(Q_{p}^{*}, h\right)$ respectively have an extremum for:

$$
\hat{k}=h \frac{e}{g} \text { and } \hat{h}=k \frac{g}{e}
$$

This results comes directly from the first order condition of each derivative function

$$
\frac{\partial C O_{2}\left(Q_{p}^{*}, k\right)}{\partial k}=0 \text { and } \frac{\partial C O_{2}\left(Q_{p}^{*}, h\right)}{\partial h}=0 .
$$

An increase in the order unit cost $k$ can have a harmful impact on the environment. It depends finally on the relationship between $h, k, e$ and $g$. This result is also explained by theorem 1 . 
For a given set of parameters $(h, e, g)$, when $k<h e / g$, an optimal order quantity $Q_{p}^{*}<Q_{e}^{*}$ is obtained. An increase of $k$ will therefore generate an increase of $Q_{p}^{*}$ which is closer to $Q_{e}^{*}$, thus causing a decrease in carbon emissions (see figure 1). When $k=h e / g$, the two optimal quantities $Q_{p}^{*}$ and $Q_{e}^{*}$ are equal, and therefore, the firm optimizes its economic and environmental efficiency. If $k>h e / g$, then $Q_{p}^{*}>Q_{e}^{*}$, and therefore $\mathrm{CO} 2$ emissions will increase further. Figure 2 illustrates this result for a given set of parameters.
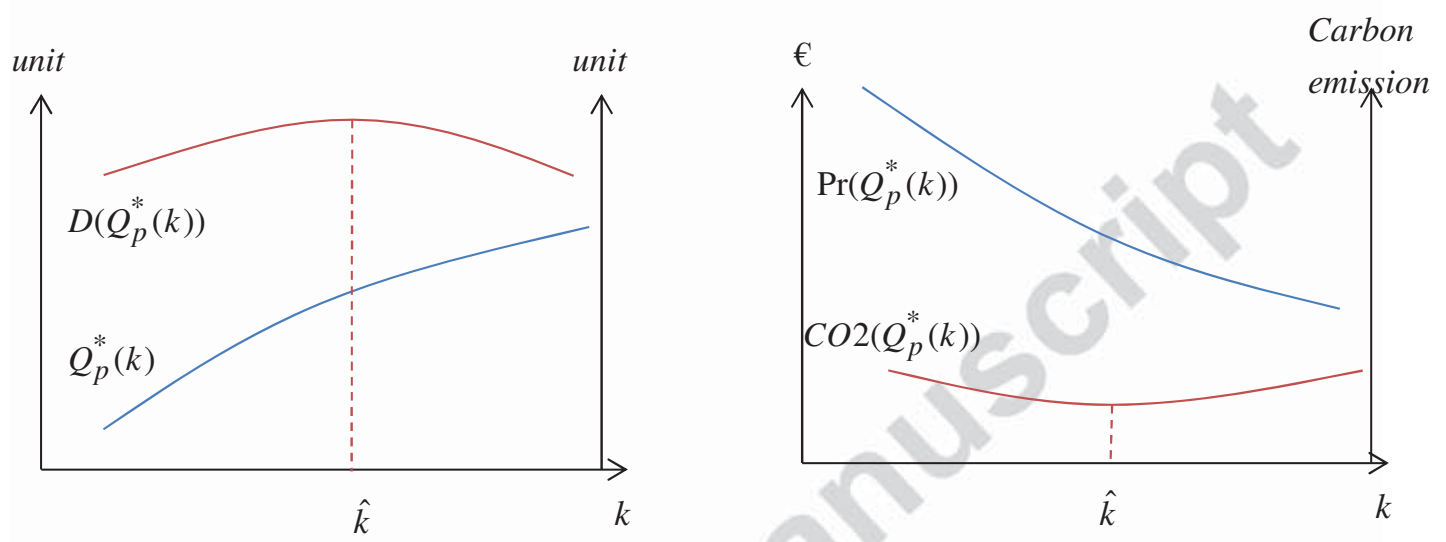

Figure 2: Evolution of order quantity, demand, emissions and profit with ordering cost.

By focusing on the performance indicator defined in (7), an increase of $k$ generates a decrease of $\kappa\left(Q_{p}^{*}\right)$ until $\hat{k}\left(\left.\frac{\partial \kappa\left(Q_{p}^{*}\right)}{\partial k}\right|_{k=\hat{k}}=0\right)$ and then $\kappa\left(Q_{p}^{*}\right)$ increases. This result once again is consistent with property 1 and theorem 1 . It confirms that the evolution of a parameter is not a sufficient condition for an overall decrease in carbon emissions. The parameter $k$ can be associated with the price of oil. Thus, an increase in the price (all other parameters remaining equal) will change the ordering policy of the retailer by an increase in the order quantity. The weight of the storage will be more important and this can generate an increase in emissions if the emissions unit structure is unfavorable to storage.

\subsection{Impact of $\mathrm{CO} 2$ elasticity}

In formula (4), a modification of consumer environmental awareness is captured by the elasticity indicator . Thus, an increase of corresponds to consumers' expected increased sustainability, which induces a decrease in the demand related to $\mathrm{CO} 2$ emissions. If 
$e / g=k / h$, then the retailer optimizes both environmental and economic functions for all parameters. Otherwise, there exists no elasticity level to reach this twofold objective (complex solution to $\left.Q_{p}^{*}(\delta)=Q_{e}^{*}(\delta)\right)$. For $e / g \neq k / h$, one obtains:

$$
\frac{\partial \operatorname{Pr}\left(Q_{p}^{*}\right)}{\partial \delta}=0 \text { for } \quad \widehat{\delta}=\frac{2(w-r)^{2}(\alpha-\beta w)-(k+e \lambda)(h+g \lambda)}{(w-r)(e(h+2 g(s+t))+g k)}
$$

The convexity of the profit function cannot be proved due to the complexity of its form. Nevertheless, for all simulations, either $\widehat{\delta} \leq 0$ and the profit function decreases with $\delta$, or $\widehat{\delta}>0$ and the profit function decreases then increases with $\delta$.

This results illustrates that, above some threshold, the retailer may increase its profit with an increasing consumer's awareness. It is interesting to note that for an initial low elasticity $\delta$, the retailer will be penalized with higher consumer's awareness. However, if the consumer becomes increasingly sensitive to sustainability, retailer will decrease sufficiently emissions to compensate an increase of $\delta$.

The sign of $\partial Q_{p}^{*} / \partial \delta$ depends on the parameters but the complexity of the equations does not allow to obtain overall demonstrable analytical results.

Consider the following set of parameters:

$\alpha=10 ; w=10 ; r=0 ; \beta=0.1 ; t=0 ; s=0 ; g=1 ; e=1 ; k=1 ; h=0.5$. Figure 3 is obtained by varying the environmental sensitivity with an exogenous price. So, even if emissions decrease overall with an increase in $\delta$, the marginal importance of emissions increases because the overall demand decreases. This important point highlights some ambiguous mechanisms linked to sustainable strategies: under parameters conditions, increasing carbon sensitivity encourages the retailer to reduce its emissions but this reduction does not compensate the decrease in demand. In the case of commodities (food products, etc.), there may be a substitution from eco-friendly products to "classical" products, and then a total raise of carbon emissions. 


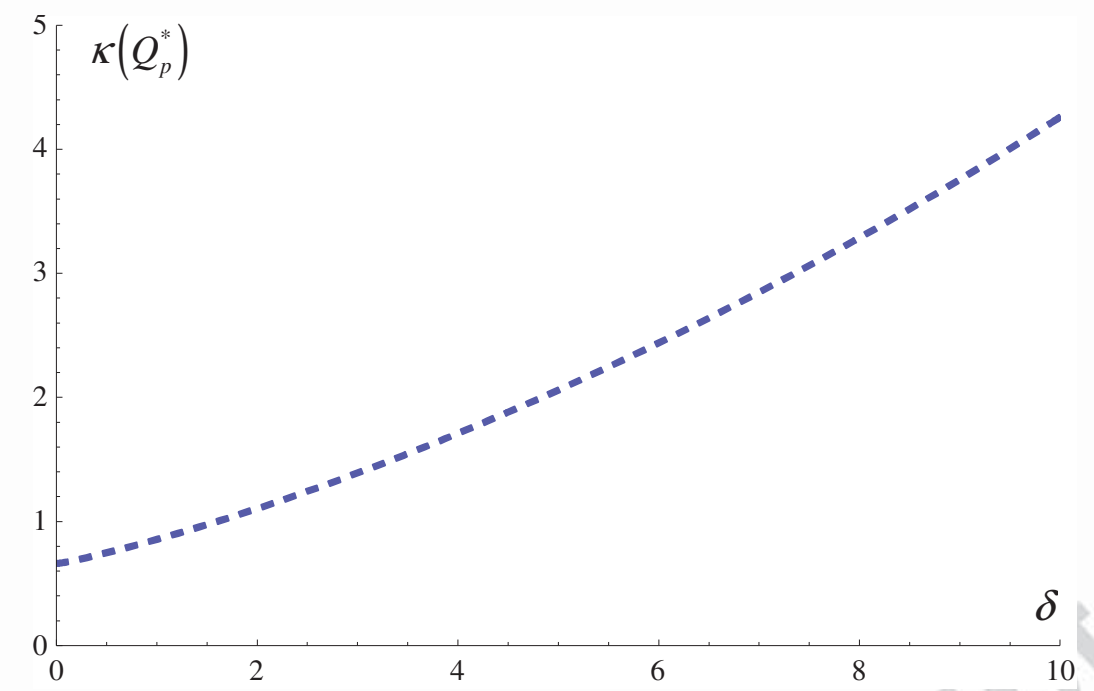

Figure 3: Marginal carbon emissions behavior with consumer environmental awareness

Furthermore, excess $\delta$ could lead a firm to not produce (under this threshold value, the optimal quantity and/or the profit would be negative). So, all other factors being equal, an oversensitivity to $\mathrm{CO} 2$ emissions could totally block a company's strategy of holding and ordering, the strategy of a $\mathrm{CO} 2$ decrease not being sufficient to outweigh the increase of $\delta$. In the case of excess environmental sensitivity, the retailer will probably adjust its price to generate profit. This notion will be discussed in the next section.

\section{Analysis with an endogenous price}

Previously, the stock management policy was discussed with an exogenous price. Some mechanisms are also observed independently of a retailer's pricing behavior. In this section, the retailer optimizes its profits through both inventory management policy $\left(Q_{p}\right)$ and sales price policy $\left(w_{p}\right)$. Thus: $\underset{Q_{p}, w_{p}}{\operatorname{Max}} \operatorname{Pr}\left(Q_{p}, w_{p}\right)$ and $\underset{Q_{e}, w_{e}}{\operatorname{Min}} \operatorname{Pr}\left(Q_{e}, w_{e}\right)$ are investigated.

In fact, the $\mathrm{CO} 2$ minimization has not an economic sense in this case. To minimize its emissions, the firm will hardly increase its price so that the demand will tend to 0 (and $Q_{e}$ will tend to 0 too).

In the profit's maximization case, the first order conditions lead to: 


$$
\begin{aligned}
& \frac{\partial \operatorname{Pr}}{\partial Q_{p}}=0 \\
& \frac{\partial \operatorname{Pr}}{\partial w_{p}}=0
\end{aligned} \rightarrow\left\{\begin{array}{c}
Q_{p}^{*}\left(w_{p}^{*}\right)=-e \delta+\frac{\sqrt{A(k+e \lambda)(h+g \lambda)}}{h+g \lambda} \\
w_{p}^{*}\left(Q_{p}^{*}\right)=\frac{Q_{p}^{*}\left(2 \alpha+2 \beta r-g \delta Q_{p}^{*}\right)+2 \beta(k+e(s+t))}{4 \beta Q_{p}^{*}}
\end{array}\right.
$$

with $A=2 \alpha-2 w_{p}^{*} \beta+e g \delta^{2}$ and $\lambda=s+t+\delta(w-r)$.

The second order conditions cannot be proved formally due to the complexity of the Hessian matrix. Nevertheless, it is proved that $\partial^{2} \operatorname{Pr} / \partial Q_{p}^{2}<0$ and $\partial^{2} \operatorname{Pr} / \partial w_{p}^{2}<0$ for all $\left(Q_{p}, w_{p}\right)$.

For all following simulations, it is verified that the determinant of the Hessian matrix is positive for $\left(Q_{p}^{*}, w_{p}^{*}\right)$ and thus that the above solutions are optimum.

Several simulations are described afterwards, based on the following parameter values: $\alpha=10 ; r=0 ; Z=10$.

Considering a lack of carbon tax and cap-and-trade mechanism $(s=t=0)$, optimal solutions are computed for different values of price and carbon sensitivities in the three cases are presented in Table 1 . In order to evaluate the tax utility, case $2(g / e<h / k)$ is closely examined in Table 2. 
Table 1: Order quantity and price optimum without carbon tax and cap-and-trade

\begin{tabular}{|c|c|c|c|c|c|c|c|c|c|}
\hline & & & & $w_{p}$ & $Q_{p}$ & D & $\mathrm{CO} 2$ & $\mathrm{Pr}$ & $\kappa$ \\
\hline \multirow{6}{*}{$\begin{array}{l}\overrightarrow{0} \\
\tilde{J} \\
\tilde{J}\end{array}$} & \multirow{6}{*}{$\begin{array}{l}g=1 \\
e=1 \\
h=1 \\
k=1\end{array}$} & \multirow{2}{*}{$\beta=0.1$} & $\delta=0.1$ & 49.39 & 3.08 & 4.75 & 3.08 & 231 & 0.65 \\
\hline & & & $\delta=1$ & 43.97 & 2.49 & 3.11 & 2.49 & 134 & 0.80 \\
\hline & & \multirow{2}{*}{$\beta=0.2$} & $\delta=0.1$ & 24.78 & 3.08 & 4.74 & 3.08 & 114 & 0.65 \\
\hline & & & $\delta=1$ & 22.09 & 2.49 & 3.09 & 2.49 & 66 & 0.81 \\
\hline & & \multirow{2}{*}{$\beta=0.3$} & $\delta=0.1$ & 16.57 & 3.07 & 4.72 & 3.07 & 75 & 0.65 \\
\hline & & & $\delta=1$ & 14.8 & 2.48 & 3.07 & 2.48 & 43.08 & 0.81 \\
\hline \multirow{6}{*}{ 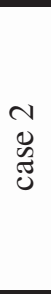 } & \multirow{6}{*}{$\begin{array}{l}\mathrm{g}=1 \\
\mathrm{e}=1 \\
\mathrm{~h}=1 \\
\mathrm{k}=0.8\end{array}$} & \multirow{2}{*}{$\beta=0.1$} & $\delta=0.1$ & 49.38 & 3.03 & 4.75 & 3.08 & 232 & 0.65 \\
\hline & & & $\delta=1$ & 43.94 & 2.49 & 3.11 & 2.49 & 134 & 0.80 \\
\hline & & \multirow{2}{*}{$\beta=0.2$} & $\delta=0.1$ & 24.76 & 2.99 & 4.74 & 3.09 & 115 & 0.65 \\
\hline & & & $\delta=1$ & 22.07 & 2.47 & 3.1 & 2.49 & 66 & 0.80 \\
\hline & & \multirow{2}{*}{$\beta=0.3$} & $\delta=0.1$ & 16.56 & 2.95 & 4.73 & 3.09 & 75.48 & 0.65 \\
\hline & & & $\delta=1$ & 14.78 & 2.46 & 3.08 & 2.48 & 43.33 & 0.81 \\
\hline \multirow{6}{*}{ 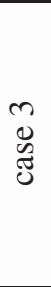 } & \multirow{6}{*}{$\begin{array}{l}\mathrm{g}=1 \\
\mathrm{e}=1 \\
\mathrm{~h}=0.7 \\
\mathrm{k}=1\end{array}$} & \multirow{2}{*}{$\beta=0.1$} & $\delta=0.1$ & 49.37 & 3.17 & 4.75 & 3.08 & 232 & 0.65 \\
\hline & & & $\delta=1$ & 43.93 & 2.51 & 3.11 & 2.49 & 135 & 0.80 \\
\hline & & \multirow{2}{*}{$\beta=0.2$} & $\delta=0.1$ & 24.75 & 3.23 & 4.74 & 3.09 & 115 & 0.65 \\
\hline & & & $\delta=1$ & 22.06 & 2.51 & 3.09 & 2.49 & 66 & 0.81 \\
\hline & & \multirow{2}{*}{$\beta=0.3$} & $\delta=0.1$ & 16.55 & 3.27 & 4.73 & 3.09 & 75.64 & 0.65 \\
\hline & & & $\delta=1$ & 14.77 & 2.52 & 3.09 & 2.48 & 43.46 & 0.80 \\
\hline
\end{tabular}

An increased sensitivity to $\mathrm{CO} 2$ (via $\delta$ ) generates a decrease in price, quantity, $\mathrm{CO} 2$ emissions, and profit as well as an increase in the marginal emission indicator. This result tends to confirm an empirical analysis showing that the overall change in purchasing is more significant for cheaper and green-labeled products (Vanclay et al., 2011). An inventory policy linked to $\mathrm{CO} 2$ and price also allows a more sustainable strategy.

Moreover, increased sensitivity to price generates a decrease in optimal price, profit and marginal emission indicators. However, certain situations generate an increase in quantity (case 3) and emissions (case 2 and 3 with $\delta=0.1$ ). When consumers are more price dependent, retailers lower their price and capture an increased demand $D\left(Q_{p}^{*}\right)$. When environmental sensitivity is low, the influence of inventory costs is stronger than the influence of carbon emission costs. 
Table 2: Impact of a carbon tax on the optimal order quantity and price

\begin{tabular}{|c|c|c|c|c|c|c|c|c|}
\hline & & & $w_{p}$ & $Q_{p}$ & D & $\mathrm{CO} 2$ & $\mathrm{Pr}$ & $\kappa$ \\
\hline \multirow{6}{*}{$\begin{array}{ll}\text { N } & 0 \\
0 & \text { II } \\
\tilde{J} & -1\end{array}$} & \multirow{2}{*}{$\beta=0.1$} & $\delta=0.1$ & 49.38 & 3.03 & 4.75 & 3.08 & 232 & 0.65 \\
\hline & & $\delta=1$ & 43.94 & 2.49 & 3.11 & 2.49 & 134 & 0.80 \\
\hline & \multirow{2}{*}{$\beta=0.2$} & $\delta=0.1$ & 24.76 & 2.99 & 4.74 & 3.08 & 115 & 0.65 \\
\hline & & $\delta=1$ & 22.07 & 2.47 & 3.1 & 2.49 & 66 & 0.80 \\
\hline & \multirow{2}{*}{$\beta=0.3$} & $\delta=0.1$ & 16.56 & 2.95 & 4.73 & 3.08 & 75.48 & 0.65 \\
\hline & & $\delta=1$ & 14.78 & 2.46 & 3.08 & 2.48 & 43.33 & 0.81 \\
\hline \multirow{6}{*}{$\begin{array}{l}\tilde{J}^{-} \\
\tilde{J} \\
\tilde{J}\end{array}$} & \multirow{2}{*}{$\beta=0.1$} & $\delta=0.1$ & 49.54 & 3.03 & 4.74 & 3.08 & 229 & 0.65 \\
\hline & & $\delta=1$ & 44.16 & 2.48 & 3.1 & 2.49 & 132 & 0.80 \\
\hline & \multirow{2}{*}{$\beta=0.2$} & $\delta=0.1$ & 24.93 & 3 & 4.71 & 3.07 & 112 & 0.65 \\
\hline & & $\delta=1$ & 22.29 & 2.46 & 3.07 & 2.48 & 64 & 0.81 \\
\hline & \multirow{2}{*}{$\beta=0.3$} & $\delta=0.1$ & 16.72 & 2.97 & 4.68 & 3.06 & 72 & 0.65 \\
\hline & & $\delta=1$ & 15 & 2.44 & 3.04 & 2.46 & 41 & 0.81 \\
\hline \multirow{6}{*}{ 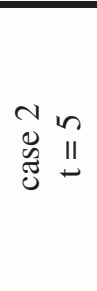 } & \multirow{2}{*}{$\beta=0.1$} & $\delta=0.1$ & 50.2 & 3.03 & 4.67 & 3.06 & 217 & 0.66 \\
\hline & & $\delta=1$ & 45 & 2.46 & 3.03 & 2.46 & 122 & 0.81 \\
\hline & \multirow{2}{*}{$\beta=0.2$} & $\delta=0.1$ & 25.6 & 2.99 & 4.58 & 3.03 & 99 & 0.66 \\
\hline & & $\delta=1$ & 23.19 & 2.41 & 2.94 & 2.42 & 54 & 0.82 \\
\hline & \multirow{2}{*}{$\beta=0.3$} & $\delta=0.1$ & 17.4 & 2.95 & 4.48 & 2.99 & 60 & 0.67 \\
\hline & & $\delta=1$ & 15.92 & 2.37 & 2.84 & 2.38 & 31 & 0.84 \\
\hline
\end{tabular}

The first observation is that a tax leads to a decrease in total emissions and therefore the mechanism reaches its objective. However, a tax also leads to an increase in the optimal price, and therefore to a decrease in attractiveness for all consumers. This example highlights a major point of discussion about the introduction of a carbon tax and its sharing between all the actors of the supply chain (stakeholders and consumers).

Concerning an ordering policy, the optimal quantity increases if environmental sensitivity is weak, but decreases in the opposite case. This has been explained above by the relative cost of an order compared to the inventory cost (30\% lower).

\section{Concluding remarks}

Currently companies are looking for solutions to reduce carbon emissions associated with their operations. Operational adjustments, like modifying batch sizes or order quantities, have proven to be an effective way to decrease emissions. In this paper, a model is proposed that takes into account the link between an inventory policy (EOQ), total carbon emissions, and both price and environmental dependent demand. In the case of an exogenous price, optimal quantities (EOQ) that maximize a retailer's profit and minimize carbon emissions are determined. First, the increase of a carbon tax generates lower emissions, except when 
$g / e=h / k$. In this case, the optimal quantity does not depend on the carbon tax, and both economic and environmental optimality exist. Growing consumer expectation for sustainable products has a positive impact on the environment, but a negative impact on a firm's profit (in constant prices). Finally, an increase in ordering costs (due to increased transport costs: increased taxes on gas or transportation) may, in some cases, have an adverse effect on the environment. When the retailer optimizes its profit with quantity and price, an increase of environmental sensitivity leads to a decrease in price and carbon emission in some numerical examples. Moreover, a carbon tax allows an emission decrease but generates an increase of price.

In the case of an endogenous price, when a firm optimizes its profit through both its selling price and its order quantity, some experiments match with empirical observations. On the one hand, an environmental strategy is more significant for cheaper and green-labeled products. On the other hand, a public mechanism such as a carbon tax allows to decrease total emissions but to increase marginal emissions.

Further research directions may be looked into. This work could be extended to multi-level systems with manufacturer-retailer cooperation. In particular, it may be of interest to analyze a multi-level system with a wholesale price $(r)$ depending on the emission costs. For example, all transport costs could be assigned to the manufacturer, which determines its strategy by maximizing its profit with the wholesale price.

All results of this paper and the marginal analysis, with parameters defined in (7), show the complexity of environmental issues. Thus, some strategies may be effective in a given sector but implicitly, can cause an increase in emissions in other sectors. For example, if standard goods (food, habitation, health...) are considered, there will necessarily be a coexistence of a chain of green products (often more expensive) and a chain of so-called standard products (cheaper but more polluting). Finally, the strategy of a green supply chain should be compared to high quality food chains (e.g. without GMOs, non-allergenic products...). It therefore seems interesting to analyze the research on the quality of products and to develop green supply chain management insights.

Acknowledgements: authors thank the anonymous referee for his useful comments. 


\section{References}

Andriolo, A., Battini, D., Grubbström, R.W., Persona, A., Sgarbossa, F. (2014). A century of evolution from Harris's basic lot size model: survey and research agenda. International Journal of Production Economics, 155, 16-38.

Battini, D., Persona, A., Sgarbossa, F. (2014). A sustainable EOQ model: Theoretical formulation and applications. International Journal of Production Economics, 149, 145-153.

Benjaafar, S., Li, Y., Daskin, M. (2010). Carbon footprint and the management of supply chains: insights from simple models. IEEE Tr. on Automation Science and Engineering, 10 (1), 99-116.

Bonney, M., Jaber,, M.Y. (2011). Environmentally responsible inventory models: nonclassical models for a non-classical era. International Journal of Production Economics, 133 (1), 43-53.

Bouchery, Y., Ghaffari, A., Jemai, Z., Dallery, Y. (2012). Including sustainability criteria into inventory models. European Journal Of Operational Research, 222, 229-240.

Cárdenas-Barrón, L.E., Chung K-J., Treviño-Garza G. (2014), Celebrating a century of the economic order quantity model in honor of Ford Whitman Harris. International Journal of Production Economics, 155, 1-7.

Chen, X., Benjaafar, S., Elomri, A. (2013). The carbon-constrained EOQ, Operationals Research Letters, 41, 172-179.

Cholette, S., Venkat, K. (2009). The energy and carbon intensity of wine distribution: a study of logistical options for delivering wine to consumers, Journal of Cleaner Production, 17 (16), 1401-1413.

Chitra, K. (2007). In search of the green consumer: a perceptual study. Journal of Services Research, 7 (1), 173-191.

El Saadany, A.M.A., Jaber, M.Y., Bonney, M. (2011). Environmental performance measures for supply chains. Management Research Review, 34 (11), 1202-1221.

Ghosh, D., Shah, J. (2012). A comparative analysis of greening policies across supply chain structures. International Journal of Production Economics, 135 (2), 568-583.

Glock, C.H., Grosse, E.H., Ries, J.M. (2014). The lot sizing problem: a tertiary study. 
International Journal of Production Economics, 155, 39-51.

Glock, C., Jaber, M., Searcy, C. (2012). Sustainability strategies in an EPQ model with priceand quality-sensitive demand. International Journal of Logistics Management, 23 (3), 340 359.

Gonzalez, C., Korchia, M., Menuet L., Urbain, C. (2009). How do socially responsible consumers consider consumption? An approach with free associations method. Recherche et Applications en marketing, 24 (3).

Greenhouse Gas Protocol, 2012. <http://www.ghgprotocol.org $>$.

Harris, F.W. (1913). How many parts to make at once. Factory, The Magazine of Management, 10 (2), 135-136, 152.

Hua, G., Cheng, T.C.E., Wang, S. (2011). Managing carbon footprints in inventory management. International Journal of Production Economics, 132 (2), 178-185.

Khan, M., Jaber, M.Y., Guiffrid, A.L., \& Zolfaghari, S. (2011). A review of the extensions of a modified EOQ model for imperfect quality items, International Journal of Production Economics, 132(1), 1-12.

Lau, A.H.L., Lau, H.S. (2003). Effects of a demand-curve's shape on the optimal solutions of a multi-echelon inventory/pricing model. European Journal of Operational Research, 147(3), $530-548$.

Liu, Z.L., Anderson, T.D., Cruz, J.M. (2012). Consumer environmental awareness and competition in two-stage supply chains, European Journal of Operational Research, 218 (3), 602-613.

Nouira, I., Frein, Y., Hadj-Alouanec, A. (2014). Optimization of manufacturing systems under environmental considerations for a greenness-dependent demand. International Journal of Production Economics, 150, 188-198.

Salameh, M.K, Jaber, M.Y. (2000). Economic production quantity model for items with imperfect quality. International Journal of Production Economics, 64 (1), 59-64.

Seuring, S. (2013). A review of modeling approaches for sustainable supply chain management. Decision Support Systems, 54 (4), 1513-1520.

Stock, J.R., Boyer, S.L., Harmon, T. (2010). Research opportunities in supply chain management. Journal of the Academy of Marketing Science, 38 (1), 32-41.

Swami, S. Shash, J. (2013). Channel coordination in green supply chain management. Journal of the Operational Research Society, 64, 336-351.

Tirole, J. (1988). The theory of industrial organization. The MIT Press, 488 p. 
Upham, P., Dendler, L. Bleda, M. (2011). Carbon labeling of grocery products: public perceptions and potential emissions reductions. Journal of Cleaner Production, 19, 348-365. Vanclay, J., Shortiss, J., Aulsebrook, S. (2011). Customer response to carbon labeling of groceries. Journal of Consumer Policy, 34 (1), 153-160.

Wahab, M.I.M., Mamun, S.M.H, Ongkunaruk, P. (2011). EOQ models for a coordinated twolevel international supply chain considering imperfect items and environmental impact. International Journal of Production Economics, 134 (1), 151-158.

Wilson, R.H. (1934). A scientific routine for stock control. Harvard Business Review, 13, 116-128. 


\section{Annexes}

For all proofs, we note $A=2(\alpha-\beta w)+e g \delta^{2}$ and $\lambda=s+t+\delta(w-r)$.

\section{Proof of proposition 1}

The second derivative of the profit function and of the carbon function are as follows:

$$
\frac{\partial^{2} \operatorname{Pr}(Q)}{\partial Q^{2}}=-\frac{A(k+e \lambda)}{(Q+e \delta)^{3}} \quad \text { and } \quad \frac{\partial^{2} C O_{2}(Q)}{\partial Q^{2}}=\frac{e A}{(Q+e \delta)^{3}}
$$

These functions are respectively concave and convex in $Q$.

Then, the optimal values $Q_{p}^{*}$ and $Q_{e}^{*}$ are determined by the first order conditions:

$$
\frac{\partial \operatorname{Pr}(Q)}{\partial Q}=0 \text { and } \frac{\partial C O_{2}(Q)}{\partial Q}=0
$$

\section{Proof of theorem 1}

This result comes from:

$$
Q_{p}^{*}-Q_{e}^{*}=\sqrt{A}\left(\frac{\sqrt{(k+e \lambda)(h+g \lambda)}}{h+g \lambda}-\frac{\sqrt{e g}}{g}\right)=\frac{\sqrt{A}(g k-h e)}{\sqrt{g(h+g \lambda)}(\sqrt{g(k+e \lambda)}+\sqrt{(h+g \lambda) e}}
$$

\section{Proof of proposition 2}

The first results are derived from the shape of first derivates:

$$
\frac{\partial \operatorname{Pr}\left(Q_{p}^{*}\right)}{\partial t}=\frac{1}{2}[2 e g \delta-\sqrt{A} B]
$$

with $\quad A=2(\alpha-\beta w)+e g \delta^{2} \Rightarrow \sqrt{A} \geq \delta \sqrt{e g}$

$$
B=\frac{g(k+e \lambda)+e(h+g \lambda)}{\sqrt{(k+e \lambda)(h+g \lambda)}}=\sqrt{e g}\left(\phi+\frac{1}{\phi}\right) \geq 2 \sqrt{e g}, \text { with } \phi=\sqrt{\frac{k / e+\lambda}{h / g+\lambda}} \geq 0
$$


Then: $\frac{\partial \operatorname{Pr}\left(Q_{p}^{*}\right)}{\partial t} \leq 0$.

Moreover:

$$
\begin{aligned}
& \frac{\partial Q_{p}^{*}}{\partial t}=\frac{(e h-g k)(k+e \lambda) A^{2}}{2(A(k+e \lambda)(h+g \lambda))^{3 / 2}} \Rightarrow \operatorname{sgn}\left(\frac{\partial Q_{p}^{*}}{\partial t}\right)=\operatorname{sgn}(e h-g k) \\
& \frac{\partial D\left(Q_{p}^{*}\right)}{\partial t}=\frac{(e h-g k)^{2} A^{2} \delta}{4(A(k+e \lambda)(h+g \lambda))^{3 / 2}} \geq 0 \\
& \frac{\partial C O_{2}\left(Q_{p}^{*}\right)}{\partial t}=-\frac{(e h-g k)^{2} A^{2}}{4(A(k+e \lambda)(h+g \lambda))^{3 / 2}} \leq 0
\end{aligned}
$$

\section{Proof of proposition 3}

One has:

$$
\frac{\partial \operatorname{Pr}\left(Q_{p}^{*}\right)}{\partial s}=Z+e g \lambda-\frac{\sqrt{A}(g(k+e \lambda)+e(h+g \lambda))}{2(k+e \lambda)(h+g \lambda)} .
$$

Then:

$$
\frac{\partial \operatorname{Pr}\left(Q_{p}^{*}\right)}{\partial s}=0 \text { for } s=\frac{(e h-g k)(Z+e g \delta) \sqrt{D}-D(g(k+e \lambda)+e(h+g \lambda))}{2 e g D}
$$

With

$$
D=Z^{2}-2 e g(\alpha-\beta w)+2 e g Z \delta .
$$

$s$ exists if: $D \geq 0$ and $\frac{(e h-g k)(Z+e g \delta) \sqrt{D}-D(g(k+e \lambda)+e(h+g \lambda))}{2 e g D} \geq 0$.

Moreover:

$$
\frac{\partial Q_{p}^{*}}{\partial s}=\frac{(e h-g k)(k+e \lambda) A^{2}}{2(A(k+e \lambda)(h+g \lambda))^{3 / 2}} \Rightarrow \operatorname{sgn}\left(\frac{\partial Q_{p}^{*}}{\partial s}\right)=\operatorname{sgn}(e h-g k)
$$




$$
\begin{aligned}
& \frac{\partial D\left(Q_{p}^{*}\right)}{\partial s}=\frac{(e h-g k)^{2} A^{2} \delta}{4(A(k+e \lambda)(h+g \lambda))^{3 / 2}} \geq 0 \\
& \frac{\partial C O_{2}\left(Q_{p}^{*}\right)}{\partial s}=-\frac{(e h-g k)^{2} A^{2}}{4(A(k+e \lambda)(h+g \lambda))^{3 / 2}} \leq 0
\end{aligned}
$$


- We propose an inventory model that takes into carbon emissions of the inventory policy.

- The final demand is dependent of both price and carbon emissions.

- We analyse management efficiency under economic and environmental objectives.

- A carbon tax leads to more sustainability and sometimes to a greater price.

- Increase of some logistics parameters may increase carbon emissions. 